\title{
LittéRéalité, 1988-1998
}

L es revues s'en viennent; les revues s'en vont, car l'éphémère régit la vie de toute revue littéraire. Etre pour vite disparaître; la déconstruction semble s'inscrire dans sa nature même. Conscients de cette ironie vitale de la revue, Yves Bonnefoy et ses collaborateurs, tous des représentants éminents de la poésie moderne, nommèrent leur revue des années $60 \mathrm{~L}$ 'Éphémère, afin de rappeler cette fragilité d'insectes qui disparaissent peu après leur naissance.

La revue est toujours de l'actualité; elle est un miroir de son époque. Elle renaît tout en disparaissant: elle demeure contemporaine. Ainsi affirme Michel Deguy:

Les traits sous lesquels se présente traditionnellement une revue, loin d'en vieillir le genre avec les générations successives, le maintiennent en bonne condition, en accord avec l'air, vicié même, de ce temps. Le moderne, dans ce cas, se succède heureusement à lui même. Quels traits? La diversité des propos, l'apposition des thèmes, la condensation et la fragmentation, l'éclipse et le retour, l'éphéméritude, l'appropriation collective, ou, si vous préférez, l'esprit commun d'un "nous" au travail pour qui "la poésie doit être facile" (Lautréamont) — voire la "psyché entre amis" selon la formule de Hölderlin (LittéRéalité Vol. VI, $\mathrm{N}^{\circ} 2$, 1994).

Décidément les conditions de la revue ne sont pas heureuses! Et pourtant, LittéRéalité a dix ans. Raison de se réjouir. Elle survit, malgré les nombreux obstacles, matériels et idéologiques, confrontés presque quotidiennement. Après vingt numéros, la "petite revue" a acquis une identité solide et unique. On la reconnaît; on la cite (dans Inédit, Les Saisons du poème, La Toison d'or, Lettres québécoises, etc.); on est fier de publier dans ses pages. Son succès est évident dans sa longévité relativement exceptionnelle, dans les collaborateurs de renommée qu'elle attire et dans son lectorat constant, et même grandissant. 
LittéRéalité a un caractère double: elle paraît deux fois par année; elle se veut francophone, mais bilingue; et elle se déclare, enfin, un forum à la fois de critique et de création. En Amérique du Nord, et surtout au Canada, aucune autre revue ne lui ressemble. L'objectif, qu'elle s'est fixé dès le début, de promouvoir l'étude de la littérature francophone, aussi bien que d'encourager la création et l'édition dans ce domaine, demeure inébranlable. Chaque numéro contribue avec ténacité et imagination à la réalisation de cet objectif.

Les chiffres parlent éloquemment de la présence de LittéRéalité: plus de cent cinquante articles sur la littérature francophone y ont été publiés; plus de deux cents poètes, de Guillevic et Deguy à Chedid et Brossard, y ont contribué des textes inédits; et on a recensé dans ses pages plus de cent trente nouvelles parutions.

On est surtout fier des cinq numéros spéciaux dont chacun a porté l'attention sur la littérature d'une région francophone particulière: La Poésie contemporaine au Québec Vol. II, $\mathrm{N}^{\circ} 2$ (Automne 1990); La littérature franco-ontarienne d'aujourd'hui Vol. IV, No 1 (Printemps 1992); Accent sur la littérature acadienne Vol. V, No2 (Hiver 1993); La Poésie contemporaine en France Vol. VI, No 2 (Automne/Hiver 1994); Aspects de la littérature francophone des Antilles Vol. X, $\mathrm{N}^{\circ} 1$ (Printemps/Eté 1998). On espère continuer cette série pour qu'on puisse lentement constituer une image prismatique de l'expression contemporaine du monde littéraire francophone. Fière de ses origines canadiennes, la revue s'engage de plus en plus à dépasser ses frontières pour s'affirmer, pour se renouveler et pour mieux servir ses objectifs.

On aspire donc à poursuivre cette activité encore une décennie, peut-être, avec de la gratitude pour chaque nouveau numéro et, toujours, avec la conscience que les saisons passent et que c'est dans la nature des éphémères de disparaître, sinon de subir une métamorphose et atteindre un stade plus accompli, plus beau, plus créateur. 